\title{
Use of complementary and alternative medicines in haemodialysis patients: a cross-sectional study from Palestine
}

Sa'ed H. Zyoud ${ }^{1,2,3^{*}}$, Samah W. Al-Jabi ${ }^{2}$, Waleed M Sweileh ${ }^{4}$, Ghada H. Tabeeb ${ }^{5}$, Nora A. Ayaseh ${ }^{5}$, Mayas N. Sawafta ${ }^{5}$, Razan L. Khdeir ${ }^{5}$, Diana O. Mezyed ${ }^{5}$, Dala N. Daraghmeh ${ }^{5}$ and Rahmat Awang ${ }^{3}$

\begin{abstract}
Background: Complementary and alternative medicine (CAM), and herbal therapies, are accepted worldwide, and have been important from medical, sociological and economic perspectives, among haemodialysis (HD) patients. The primary aim of this study was to evaluate the use of CAM among patients with end-stage renal disease (ESRD) who are undergoing HD.

Methods: Face-to-face interviews of patients with ESRD undergoing HD from ten outpatient renal departments at a national level in Palestine were conducted from June 2014 to January 2015. A survey questionnaire, which included questions on socio-demographic and clinical characteristics, and on the CAM therapies that were used, was administered.

Results: Out of 267 patients interviewed, 172 patients used at least one type of CAM in the last month prior to the interview, and thus the utilisation rate was $64.4 \%$. Forty one (15.4\%) patients reported using one type of CAMs, while 18. $7 \%$ used two different CAMs and $30.3 \%$ used more than two types of CAMs for their health status. Of the patients who used CAM, herbal therapies were used most often (43.5\%), followed by honey (35.6\%), diet (22.8\%), and exorcism in Islam (16.9\%). The herbal therapies mentioned most often were Nigella sativa L. (18.7 \%), followed by Salvia officinalis L. (16.9\%), and Pimpinella anisum L. (10.5\%).

Conclusions: In conclusion, the prevalence of CAM is relatively high in the selected population. Most patients used biological therapies such as herbal remedies, thus highlighting a greater need for patient education regarding CAM therapies and possible herb-drug interactions. Health care providers must be aware of the potential benefits and risks related to CAM use. There is a need for more clinical research pertaining to CAM to reach stronger evidence regarding potential benefits and risks related to CAM use.
\end{abstract}

Keywords: Haemodialysis, End-stage renal disease, Complementary and alternative medicine, Herbal medicine, Palestine

\section{Background}

Haemodialysis (HD) is the first-line treatment for patients with end-stage renal disease (ESRD), designed to replace kidney function, and it is the most extensively used technique worldwide [1-3]. Complementary and alternative medicine (CAM), or herbal therapies, are extremely popular worldwide and have been important among

\footnotetext{
*Correspondence: saedzyoud@yahoo.com; saedzyoud@najah.edu

'Poison Control and Drug Information Center (PCDIC), College of Medicine and Health Sciences, An-Najah National University, Nablus 44839, Palestine ${ }^{2}$ Department of Clinical and Community Pharmacy, College of Medicine and Health Sciences, An-Najah National University, Nablus 44839, Palestine Full list of author information is available at the end of the article
}

HD patients from medical, sociological and economic perspectives [4-6]. CAM may provide new therapeutic opportunities for HD patients with the target of enhancing quality of life and improving symptoms [7-9].

The most widely used CAM therapies include biologically based therapies (e.g. herbal) and mind-body medicine (e.g. yoga, spiritual healing/prayer, meditation, and hypnosis). Despite the ubiquitous use of CAM at a global level in a broad range of illnesses or populations, there is limited data concerning the use of CAM or herbal therapies in patients with ESRD [7, 8, 10-12]. To our knowledge, there were several studies conducted on CAM, considering aspects 
other than ESRD type, such as CAM among Palestinian hypertensive patients [13], diabetes mellitus patients [14], cancer patients [15], or the general public [16]. There were also several studies conducted on herbal therapies that considered aspects other than ESRD type, such as herbal therapies among cancer patients [17], university students [18], geriatric patients [19], or in pregnancy [20, 21]. An extensive search did not reveal information concerning the use of CAM or herbal among HD patients in the Arab Middle East where medicinal herbs, or some types of CAM such as honey, prayers, reading holy books, Al-Hijama, fasting, or exorcism in Islam are an integral part of the culture and religion [22-27]. This study was performed to determine the prevalence and types of CAM and herbal therapies used among Palestinian patients with HD. The present study aims to contribute to this growing area of research by helping in plan the interventions needed to improve the self-use of CAM or herbal therapies, and by identifying the most commonly used CAM or herbal therapies which may form a data-base for further research. Understanding patterns of CAM therapies used in HD patients will not only help healthcare providers to provide more informed clinical care but also assist policymakers in creating the appropriate frameworks for future policy and direct and encourage researchers to conduct clinical research pertaining to CAM to reach stronger evidence regarding potential benefits and risks related to CAM use.

\section{Methods}

\section{Study design and setting}

Data in this study was obtained from a cross-sectional study carried out during the period: June 2014 to January 2015. Participants were recruit from ten different settings (Abu Al hasan Al Kassem Hospital, Al Hussein Hospital, Alia Hospital, An-najah National University teaching Hospital, Darwish Nazal Hospital, Jericho Government Hospital, Khalil Suliman Hospital, Ramallah's Sons Wing Hospital, Thabit Thabit Hospital, and Yasser Arafat Hospital) representing government and non-government sectors in West-Bank, Palestine to include a broad spectrum of participant characteristics [28].

\section{Study population}

Consecutive dialysis patients from 10 outpatient renal departments with associated dialysis units were included. Information regarding number and geographical distribution of dialysis units in West-Bank as well as the total number of HD patients (740) at the time of study were obtained from the Palestinian Ministry of Health and Palestinian Central Bureau of Statistics [29].

\section{Sample size and sampling techniques}

Raosoft sample size calculator, a web-based calculator, was used to estimate the required sample size assuming that $50 \%$ of the HD patients used CAM for their health status, margin of error set at 0.05 , and assuming a confidence level of $95 \%$ [30]. The required sample size was calculated to be 254 HD patients, which was increased to 277 for more accuracy, to account for unusable questionnaires and potential non-responses, and to increase the generalizability of the obtained results. Participants who met the following criteria were included in the study: (1) patients younger than 18; (2) confirmed diagnosis of ESRD; and (3) on regular HD therapy for at least 6 months. Those patients who were seriously ill or had major psychiatric disorders at the time of study were excluded.

\section{Research instrument}

A quantitative survey instrument was formed based on questionnaires from previous studies [7, 8, 10-12]. The questionnaires were prepared and evaluated for content validity by a group of experts in the fields of nephrology, alternative medicine, clinical pharmacy and biostatisticians. The clarity and readability of the questionnaire was pre-tested in a pilot study of 16 patients. The results of the pilot sample were not included in the final analysis. Feedback from the participants was used to modify and adjust the questionnaire to reach the final version of the study tool. An additional file was provided to show detailed description of the study both in English and Arabic (Additional file 1).

The questionnaire consisted of four parts. The first part was about the socio-demographic characteristics of the participants, and recorded details of age, gender, marital status, residency, educational level, body mass index (BMI), family monthly income, smoking status, and occupational status. The second part was about the clinical characteristics of the participants, and recorded the duration of disease in months, duration of dialysis sessions in hours, number of dialysis per week, number of chronic diseases, and number of medications for chronic use. The third part of the questionnaire focused on the regular consumption of CAM and participants were asked to identify what they had used in the last month before the survey. CAM therapies were categorized in a list as follows: (1) Alternative Medical Systems such as acupuncture; (2) Biologically Based Therapies such as folk medicine, vitamins, or other types of herbal products; (3) Manipulative and Body-Based Methods such as massage or physical therapies (e.g. heat and cold, or rehabilitation strategies); and (4) Mind-Body Medicine such as meditation, hypnosis, walking, or music therapy [31-38]. Exorcism in Islam (ruqya) was combined with Mind-Body Medicine, to mimic previous studies [33, 39, 40]. The last part of the questionnaire was designed to determine the types of herbal therapies that HD patients have used in selftherapy practices. HD patients were requested to provide the native name of the herb that they used as self-therapy. 
This study included all herbal remedies or other CAM which was used only for improving or curing health conditions during the dialysis care period as CAM.

\section{Statistical analysis}

All statistical analyses were conducted using the Statistical Software Package for the Social Sciences, version 15 for Windows (SPSS, Chicago, IL). For descriptive statistics, means, standard deviations (SD), and medians interquartile range $[\mathrm{IQR}])$, frequencies, and percentages were computed. Pearson Chi-Square test or Fisher's exact test was used for comparative analysis. A value of $P<0.05$ was considered significant.

\section{Results}

A total of 267 patients (139 males, 128 females; mean age $53.3 \pm 16.2$ years) receiving HD were recruited for the study. The socio-demographic data of the study participants is listed in Table 1 . The majority of patients (73.4\%) had hypertension. Approximately two thirds (67\%) had multiple chronic diseases, and $172(64.4 \%)$ were on six or more chronic medications. Around two thirds of patients (76.4 \%) were dialyzed three times weekly, 188 patients (70.4 \%) stayed on dialysis more than three hours, and the median duration of $\mathrm{HD}$ was 2 (interquartile range: $1-5$ years). Demographic and clinical characteristics of the participants are shown in Table 1.

One hundred-seventy two of the patients (64.4\%) reported the use of one or more type of CAM therapy. A total of 19 different CAMs were reported by HD patients (Table 2). A total of 486 CAM episodes were reported by all HD patients, giving an average utilisation rate of $1.8 \pm 1.9$. The CAM users among the dialysis patients had used a median of one CAM, and a maximum of nine types. Forty one $(15.4 \%)$ patients reported using one type of CAM, while $18.7 \%$ used two different CAMs and $30.3 \%$ used more than two types of CAM for their health. Of the patients who used CAM, herbal therapy was used most often ( $43.5 \%)$, followed by honey (35.6\%), diet (22.8\%), and exorcism in Islam (16.9\%); (Table 2). CAM use was distributed throughout the population in regards to the socio-demographic and clinical characteristics in Table 1. A comparison of the characteristics of users and nonusers of CAM showed that there was no significant difference ( $p$-value $>0.05)$ in all sociodemographics and clinical characteristics except in their income, and the number of dialysis sessions per week which showed a significant difference $(p$-value $<0.05)$.

A total of 20 different herbal therapies were reported by HD patients (Table 3). Herbal therapies mentioned most often were Nigella sativa L. (18.7 \%), followed by Salvia officinalis L. (16.9\%), and Pimpinella anisum L. (10.5\%); (Table 3). Fifty two (19.5\%) patients reported using one type of herbal therapy, $10.1 \%$ reported using two types of herbal therapy, and $13.9 \%$ reported using more than two types of herbal therapies for their health.

\section{Discussion}

This cross-sectional study documents the utilisation pattern of CAMs among HD in 10 haemodialysis centres in West Bank, Palestine. The participants are considered representative of patients with ESRD in Palestine since the haemodialysis centres are located in all districts of Palestine. The use of CAM has been reported among HD patients at a global level [7, 8, 10-12], however, the current study is the first to assess the use of CAM among a sample of HD patients in Palestine.

Many of the patients that we studied reported the use of certain types of CAM therapies in their health selfmanagement. These therapies were mainly home herbal remedies. Around two thirds of HD patients in our study reported the use of one, or more than one, type of CAM therapy, which is in agreement with other published studies among HD or other chronic diseases [8, 10, 41, 42]. Use of CAM or herbal remedies among Palestinian people and Arab or Muslim populations in general is driven by culture, history, sometimes religion, and sometimes by herbalists spread all over the country rather by advice from healthcare providers [22-27, 43, 44]. Based on this, the investigators did address the question "who recommends these herbs to HD patients" because of the many possible confounding factors. Furthermore, none of the herbal remedies used by HD patients are present in the essential drug list of the Palestinian ministry of health and are not covered by health insurance which made their use to be outside the context of prescribed medicines $[45,46]$.

It is noteworthy that the consumption of herbal remedies reported in our study was more prevalent in dialysis patients than that in other published data $[10,11]$. Herbal remedies were of interest in this study because they are usually considered intrinsically safe and beneficial, and are frequently consumed in large quantities by ESRD patients [10, 11, 47-49]. Nigella sativa L., and Salvia officinalis L. were among the most common herb reported in the current study as well, which is interesting because extensive research studies on Nigella sativa L., and Salvia officinalis $\mathrm{L}$. have indicated a renoprotective effects of these herbs [50-52].

However, because herbal constituents and bioactive phytochemical compounds might interact with patient's medications, their use is not always safe for HD patients [53-57]. The use of herbal medicines in HD patients seems to bear more risk compared tothe general population [11]. It is mainly due to accumulation of toxic material of herbal remedies in patients with kidney malfunction. Toxicity of herbal therapies may be caused by the different active constituents; or contaminants, or potential interactions 
Table 1 Socio-demographic and clinical characteristics of the study population $(n=267)$ and their association with CAM use

\begin{tabular}{|c|c|c|c|c|}
\hline Variable & Overall $N(\%) N=267$ & CAM users $N(\%) N=172$ & Non-CAM users $N(\%) N=95$ & $P$ value \\
\hline Age category (year) & & & & 0.093 \\
\hline$<40$ & $58(21.7)$ & $42(24.4)$ & $16(16.8)$ & \\
\hline $40-59$ & $97(36.3)$ & $66(38.4)$ & $31(32.6)$ & \\
\hline$\geq 60$ & $112(41.9)$ & $64(37.2)$ & $48(50.5)$ & \\
\hline Gender & & & & 0.899 \\
\hline Male & $139(52.1)$ & $89(51.7)$ & $50(52.6)$ & \\
\hline Female & $128(47.9)$ & $83(48.3)$ & $45(47.4)$ & \\
\hline $\mathrm{BMI}$ & & & & 0.323 \\
\hline Underweight & $24(9)$ & $16(9.4)$ & $8(9.3)$ & \\
\hline Normal & $97(36.3)$ & $71(41.8)$ & $26(30.2)$ & \\
\hline Overweight & $27(28.1)$ & $44(25.9)$ & $28(32.6)$ & \\
\hline Obese & $63(23.6)$ & $39(22.9)$ & $24(27.9)$ & \\
\hline Education & & & & 0.112 \\
\hline Not educated & $40(15.0)$ & $21(12.2)$ & $19(15)$ & \\
\hline Elementary school (primary) & $71(26.6)$ & $42(24.4)$ & $29(30.5)$ & \\
\hline High school (secondary school) & $102(38.2)$ & $69(40.1)$ & $33(34.7)$ & \\
\hline University & $54(20.2)$ & $40(23.3)$ & $14(14.7)$ & \\
\hline Income & & & & 0.006 \\
\hline Moderate to high ( $\geq 2000 \mathrm{NIS}$ ) & $100(37.5)$ & $75(43.6)$ & $25(26.3)$ & \\
\hline Low $(<2000 \mathrm{NIS})$ & $167(62.5)$ & $97(56.4)$ & $70(73.7)$ & \\
\hline Living & & & & 0.559 \\
\hline City & $84(31.5)$ & $58(33.7)$ & $26(27.4)$ & \\
\hline Village & $161(60.3)$ & $100(58.1)$ & $61(64.2)$ & \\
\hline Palestinian refugee camps & $22(8.2)$ & $14(8.1)$ & $8(8.4)$ & \\
\hline Marital Status & & & & 0.404 \\
\hline Married & $188(70.4)$ & $118(68.6)$ & $70(73.7)$ & \\
\hline Not married & $79(29.6)$ & $54(20.2)$ & $25(26.3)$ & \\
\hline Occupation & & & & 0.706 \\
\hline Unemployed & $232(86.9)$ & $148(86.0)$ & $84(88.4)$ & \\
\hline Employed & $35(13.1)$ & $24(14.0)$ & $11(11.6)$ & \\
\hline Duration of dialysis (month) & & & & 0.343 \\
\hline$<12$ & $58(21.7)$ & $40(23.3)$ & $18(18.9)$ & \\
\hline $12-49$ & 119(44.6) & $71(41.3)$ & $48(50.5)$ & \\
\hline$\geq 50$ & $90(33.7)$ & $61(35.5)$ & $29(30.5)$ & \\
\hline Number of dialysis sessions per week & & & & $<0.001$ \\
\hline$\leq 2$ & $26(9.7)$ & $14(8.1)$ & $12(12.6)$ & \\
\hline 3 & $204(76.4)$ & $144(83.7)$ & $60(63.2)$ & \\
\hline$\geq 4$ & $37(13.9)$ & $14(8.1)$ & $23(24.2)$ & \\
\hline Dialysis in a day (hours) & & & & 0.066 \\
\hline$\leq 3$ & 79 (29.6) & $43(25.0)$ & $36(37.9)$ & \\
\hline$>3-<4$ & $119(44.6)$ & $84(48.8)$ & $35(36.8)$ & \\
\hline$\geq 4$ & $69(25.8)$ & $45(26.2)$ & $24(25.3)$ & \\
\hline Transplantation history & & & & 0.830 \\
\hline Yes & $26(9.7)$ & $16(9.3)$ & $10(10.5)$ & \\
\hline
\end{tabular}


Table 1 Socio-demographic and clinical characteristics of the study population $(n=267)$ and their association with CAM use (Continued)

\begin{tabular}{llll}
\hline No & $241(90.3)$ & $156(90.7)$ & $85(89.5)$ \\
Total chronic co-morbid disease & & & $8(8.4)$ \\
Non & $26(9.7)$ & $18(10.5)$ & $22(23.2)$ \\
1 & $62(23.2)$ & $40(23.3)$ & $23(24.2)$ \\
2 & $63(23.6)$ & $40(23.3)$ & $42(44.2)$ \\
$\geq 3$ & $116(43.4)$ & $74(43.0)$ & $50(52.6)$ \\
Presence of diabetes mellitus & & & $45(47.4)$ \\
$\quad$ Yes & $122(45.7)$ & $72(59.0)$ & \\
$\quad$ No & $145(54.3)$ & $100(58.1)$ & $70(73.7)$ \\
Presence of hypertension & $196(73.4)$ & $126(73.3)$ & $25(26.3)$ \\
$\quad$ Yes & $71(26.6)$ & $46(26.7)$ & 0.091 \\
No & & $58(33.7)$ & $37(38.9)$ \\
Chronic medication (per day) & $95(35.6)$ & $114(66.3)$ & $58(61.1)$ \\
$\quad<6$ & $172(64.4)$ & & 0.940 \\
$\quad \geq 6$ &
\end{tabular}

Abbreviations: BMI body mass index, CAM Complementary and alternative medicine, NIS New Israeli Shekel

Table 2 Type of complementary and alternative medicine therapies used by the patients

\begin{tabular}{ll}
\hline CAM type & Frequency (\%) \\
\hline Biologically Based Therapies & $161(60.3)$ \\
Herbal therapy & $116(43.5)$ \\
Honey & $95(35.6)$ \\
Diet therapy & $61(22.8)$ \\
Folk medicine & $39(14.6)$ \\
Manipulative and Body-Based Methods & $39(14.6)$ \\
Massage & $26(9.7)$ \\
Physiotherapist & $23(8.6)$ \\
Mind-Body Medicine & $76(25.1)$ \\
Exorcism in Islam (ruqya) & $45(16.9)$ \\
Deep breathing & $18(6.7)$ \\
Cupping & $16(6)$ \\
Relaxation & $16(6)$ \\
Exercises & $7(2.6)$ \\
Meditation & $6(2.2)$ \\
Walking & $5(1.9)$ \\
Yoga & $3(1.1)$ \\
Hypnosis & $2(0.7)$ \\
Music & $1(0.4)$ \\
Applaud Islamist & $1(0.4)$ \\
Alence & $1(0.4)$ \\
\hline & $5(1.9)$ \\
Abrnative Medical Systems & $5(1.9)$ \\
\hline
\end{tabular}

Abbreviation: CAM Complementary and alternative medicine ${ }^{a}$ Column total exceeds $100 \%$ as data are overlapping because participants used more than one type of CAM therapy with other herbs and drugs [58]. More recent studies demonstrated that herbal medicines were associated with enhanced ESRD risk in patients with CKD [59, 60]. Senna, chamomile, and fenugreek were among the most common herbs reported in the current study as well, which is

Table 3 Distribution of herbal supplements

\begin{tabular}{ll}
\hline Herbs & Frequency (\%) \\
\hline Black cumin seed (Nigella sativa L.) & $50(18.7)$ \\
Sage (Salvia officinalis L.) & $45(16.9)$ \\
Anise (Pimpinella anisum L.) & $28(10.5)$ \\
Chamomile (Matricaria chamomilla L.) & $28(10.5)$ \\
Senna (Senna alexandrina Mill.) & $23(8.6)$ \\
Gum Arabic (Acacia senegal (L.) Willd) & $22(8.2)$ \\
Spearmint (Mentha spicata L.) & $13(4.9)$ \\
Parsley (Petroselinum crispum (Mill.) Fuss) & $12(4.5)$ \\
Fenugreek (Trigonella foenum-graecum L.) & $12(4.5)$ \\
Barley water (Hordeum vulgare L.) & $9(3.4)$ \\
Ginger (Zingiber officinale Roscoe) & $2(0.7)$ \\
Green Tea (Camellia sinensis (L.) Kuntze) & $2(0.7)$ \\
Large-leaved lime (Tilia platyphyllos Scop.) & $2(0.7)$ \\
Ivy (Hedera helix L.) & $1(0.4)$ \\
Ginseng (Panax ginseng C.A. Mey) & $1(0.4)$ \\
Hawthorn (Crataegus pinnatifida Bunge) & $1(0.4)$ \\
Caraway (Carum carvi L.) & $1(0.4)$ \\
Olive leaves (Olea europaea L.) & $1(0.4)$ \\
Cinnamon (Cinnamomum verum J. Presl) & $1(0.4)$ \\
Verbena (Verbena officinalis L.) & $1(0.4)$ \\
\hline &
\end{tabular}


interesting that senna can lead to electrolyte imbalance especially hypokalemia [61]. Chamomile and fenugreek also causes nephrotoxicities [62, 63].

Patients with renal problem are at risk of herb-drug interactions through different mechanisms (e.g. triggered activity changes of cytochrome P-450 isoenzyme metabolism and drug transport proteins for many drugs such as antihypertensives, anticoagulants, antidiabetics) [55]. Herb-drug interactions may often be unobserved because healthcare providers are not well-informed about potential herbaldrug interactions occurring in HD patients $[54,55,64,65]$. Renal impairment exposes patients to the risks of herbal remedies such as electrolyte imbalances $[11,66]$. Conversely, herbal remedies used by HD patients may have numerous possible benefits such as decreasing cutaneous pruritus, oxidative stress status, muscle cramps, and dialysis frequency $[67,68]$ or reducing proteinuria and increasing serum albumin and haemoglobin [69].

Mind-body practices such as yoga, meditation, or progressive relaxation, were the least common CAM type recognised by the participants. However, exorcism was the most common CAM type recognized by the participants. A survey of patients with ESRD in the USA reported that $42 \%$ used mind-body practices [8]. Several studies have demonstrated that mind-body practices may be beneficial for patients with ESRD [70, 71]. Mind-body medicine, such as relaxation, or exorcism often involves inexpensive self-care-based actions and appears to have minimal side effects, risks, or interactions with conventional treatment [7]. Exorcism in Islam (ruqya) is frequently used for healing in the Muslim world [33, 39, 40].

The most important implication of the current study is that in the past decade there has been a remarkable increase in the use of CAM therapies in HD patients. Healthcare providers thus need to be fully aware of the commonly used CAM therapies in their culture, and provide the correct information about the benefits or risks related to CAM therapies that may be used by HD patients $[57,65]$. It is essential for healthcare providers to be familiar with the evidence-based medicine related to herbal remedies for HD patients. Evidence is also required to evaluate CAM therapies that may be not harmful most of the time (e.g. prayer, or relaxation), compared with those that may potentially be harmful (e.g. herbal therapy). The current study provides information about the different types of CAM used by HD patients. This information should be helpful to healthcare providers in identifying patients who should be given focused education about the potential benefits and risks of unproved therapies for HD patients [57, 64, 65].

The key strengths of this study are that it includes a multi-district sample; is a national survey with a high response rate, and a large sample size. This study has some limitations worth mentioning: it is limited by its crosssectional design, and the results are subject to recall bias regarding CAM use. The convenience sampling method (non-random) is considered as source of bias since it will produce a non representative sample. Another limitation is that this study only assessed HD patients' practises towards CAM and did not survey physicians' attitude or other health care providers who also provide medical care to HD patients.

\section{Conclusions}

In conclusion, the prevalence of CAM is relatively high in the selected population. Most patients used biologicallybased therapies such as herbal remedies, thus highlighting a greater need for patient education regarding CAM therapies and their possible herb-drug interactions. Health care providers must be aware of the potential benefits and risks related to CAM use. There is a need for more clinical research pertaining to CAM to reach stronger evidence regarding potential benefits and risks related to CAM use.

\section{Additional file}

Additional file 1: Study questionnaires. This is the final version of the English and Arabic version that was used to evaluate the use of complementary and alternative medicine among patients with end-stage renal disease who are undergoing haemodialysis. (DOC 74 kb)

\section{Abbreviations}

BMl, body mass index; CAM, Complementary and alternative medicine; CKD, Chronic kidney disease; ESRD, end-stage renal disease; HD, haemodialysis; IQR interquartile range; IRB, institutional review board; SD, standard deviation

\section{Acknowledgments}

We thank all the patients who participated in the study. We would also like to thank the Palestinian Ministry of Health and An-Najah National University for their contributions to conducting this study.

\section{Authors' contributions}

SZ conceived the idea for the study, led study design and data collection, conducted the statistical analyses, interpreted the data, and drafting of manuscript; WS, SA, and RA designed the study, including the instrument development, and revised the article for important intellectual content; GT collected the data, entered the data into SPSS, and helped in the statistical analyses; and NA, MS, RK, DM, and DD collected the data and entered the data into SPSS. All authors read and approved the final manuscript and agreed on its submission.

\section{Availability of supporting data}

All data supporting the study is presented in the manuscript or available upon request from the corresponding author of this manuscript (Sa'ed H. Zyoud) at Email: saedzyoud@yahoo.com

\section{Competing interest}

The authors declare that they have no competinng interest.

\section{Consent for publication}

Not applicable.

\section{Ethics approval and consent to participate}

The protocol was approved by the Ministry of Health for all participating institutions, and the institutional review board (IRB) at An-Najah National University. Informed verbal consent was obtained before beginning the interview. 


\section{Author details}

${ }^{1}$ Poison Control and Drug Information Center (PCDIC), College of Medicine and Health Sciences, An-Najah National University, Nablus 44839, Palestine. ${ }^{2}$ Department of Clinical and Community Pharmacy, College of Medicine and Health Sciences, An-Najah National University, Nablus 44839, Palestine. ${ }^{3} \mathrm{WHO}$ Collaborating Centre for Drug Information, National Poison Centre, Universiti Sains Malaysia (USM), Penang 11800, Malaysia. ${ }^{4}$ Department of Pharmacology and Toxicology, College of Medicine and Health Sciences, An-Najah National University, Nablus 44839, Palestine. ${ }^{5}$ PharmD program, College of Medicine and Health Sciences, An-Najah National University, Nablus, Palestine.

\section{Received: 10 December 2015 Accepted: 7 July 2016}

\section{Published online: 11 July 2016}

\section{References}

1. Fissell R, Hakim RM. Improving outcomes by changing hemodialysis practice patterns. Curr Opin Nephrol Hypertens. 2013;22(6):675-80.

2. Kanagasundaram NS. Hemodialysis adequacy and the hospitalized end-stage renal disease patient-raising awareness. Semin Dial. 2012;25(5):516-9.

3. Kaur A, Davenport A. Hemodialysis for infants, children, and adolescents. Hemodial Int. 2014;18(3):573-82.

4. Butterweck V, Khan SR. Herbal medicines in the management of urolithiasis: alternative or complementary? Planta Med. 2009;75(10):1095-103.

5. Markell MS. Potential benefits of complementary medicine modalities in patients with chronic kidney disease. Adv Chronic Kidney Dis. 2005;12(3):292-9.

6. Wojcikowski K, Johnson DW, Gobe G. Herbs or natural substances as complementary therapies for chronic kidney disease: ideas for future studies. J Lab Clin Med. 2006;147(4):160-6.

7. Akyol AD, Yildirim Y, Toker E, Yavuz B. The use of complementary and alternative medicine among chronic renal failure patients. J Clin Nurs. 2011; 20(7-8):1035-43.

8. Birdee GS, Phillips RS, Brown RS. Use of complementary and alternative medicine among patients with end-stage renal disease. Evid Based Complement Alternat Med. 2013;2013:654109.

9. Duncan HJ, Pittman S, Govil A, Sorn L, Bissler G, Schultz T, Faith J, Kant S, Roy-Chaudhury P. Alternative medicine use in dialysis patients: potential for good and bad! Nephron Clin Pract. 2007;105(3):c108-13.

10. Nowack R, Balle C, Birnkammer F, Koch W, Sessler R, Birck R. Complementary and alternative medications consumed by renal patients in southern Germany. J Ren Nutr. 2009;19(3):211-9.

11. Roozbeh J, Hashempur MH, Heydari M. Use of herbal remedies among patients undergoing hemodialysis. Iran J Kidney Dis. 2013;7(6):492-5.

12. Erdoğan Z, Çınar S, Şimşek S. The relationship between hopelessness level and the use of complementary medicine methods in hemodialysis patients. Spatula DD-Peer Reviewed J Complement Med Drug Discovery. 2013;3(3):107-12.

13. Ali-Shtayeh MS, Jamous RM, Jamous RM, Salameh NM. Complementary and alternative medicine (CAM) use among hypertensive patients in Palestine. Complement Ther Clin Pract. 2013;19(4):256-63.

14. Ali-Shtayeh MS, Jamous RM, Jamous RM. Complementary and alternative medicine use amongst Palestinian diabetic patients. Complement Ther Clin Pract. 2012;18(1):16-21.

15. Ben-Arye E, Hamadeh AM, Schiff E, Jamous RM, Dagash J, Jamous RM, Agbarya A, Bar-Sela G, Massalha E, Silbermann M, et al. Compared perspectives of Arab patients in Palestine and Israel on the role of complementary medicine in cancer care. J Pain Symptom Manage. 2015;49(5):878-84.

16. Sawalha AF. Complementary and alternative medicine (CAM) in Palestine: use and safety implications. J Altern Complement Med. 2007;13(2):263-9.

17. Ali-Shtayeh MS, Jamous RM, Jamous RM. Herbal preparation use by patients suffering from cancer in Palestine. Complement Ther Clin Pract. 2011;17(4):235-40.

18. Sawalha AF, Sweileh WM, Zyoud SH, Jabi SW. Self-therapy practices among university students in Palestine: focus on herbal remedies. Complement Ther Med. 2008;16(6):343-9.

19. Zyoud SH, Abd-Alhafez AB, Hussein AO, Abu-Shehab IS, Al-Jabi SW, Sweileh WM. Patterns of use of medications, herbal products and nutritional supplements and polypharmacy associating factors in Palestinian geriatric patients. Eur Geriatr Med. 2014;5(3):188-94.

20. Ali-Shtayeh MS, Jamous RM, Jamous RM. Plants used during pregnancy, childbirth, postpartum and infant healthcare in Palestine. Complement Ther Clin Pract. 2015;21(2):84-93.

21. Al-Ramahi R, Jaradat N, Adawi D. Use of herbal medicines during pregnancy in a group of Palestinian women. J Ethnopharmacol. 2013;150(1):79-84.
22. Jazieh AR, Al Sudairy R, Abulkhair O, Alaskar A, Al Safi F, Sheblaq N, Young S, Issa $\mathrm{M}$, Tamim $\mathrm{H}$. Use of complementary and alternative medicine by patients with cancer in Saudi Arabia. J Altern Complement Med. 2012; 18(11):1045-9.

23. Akhu-Zaheya LM, Alkhasawneh EM. Complementary alternative medicine use among a sample of Muslim Jordanian oncology patients. Complement Ther Clin Pract. 2012;18(2):121-6.

24. Ching SM, Zakaria ZA, Paimin F, Jalalian M. Complementary alternative medicine use among patients with type 2 diabetes mellitus in the primary care setting: a cross-sectional study in Malaysia. BMC Complement Altern Med. 2013;13:148.

25. Saad B, Azaizeh H, Said O. Tradition and perspectives of arab herbal medicine: a review. Evid Based Complement Alternat Med. 2005;2(4):475-9.

26. Azaizeh H, Saad B, Khalil K, Said O. The state of the art of traditional arab herbal medicine in the eastern region of the mediterranean: a review. Evid Based Complement Alternat Med. 2006;3(2):229-35.

27. Ali-Shtayeh MS, Yaniv Z, Mahajna J. Ethnobotanical survey in the Palestinian area: a classification of the healing potential of medicinal plants. J Ethnopharmacol. 2000;73(1-2):221-32.

28. Zyoud SH, Daraghmeh DN, Mezyed DO, Khdeir RL, Sawafta MN, Ayaseh NA, Tabeeb GH, Sweileh WM, Awang R, Al-Jabi SW. Factors affecting quality of life in patients on haemodialysis: a cross-sectional study from Palestine. BMC Nephrol. 2016;17(1):44.

29. Ministry of Health, Palestinian Health Information Center. Health Status, Palestine, 2013. 2014 [cited 2014 June 20]; Available from: http://www.moh. ps/Content/Books/kD3bquHr7jbwK9f6VQJAsLDCuckgEDICZUFa9ssb62m9Ei m2le562D_ECDSNEboZRJwc6HyiggSMzKUPMeDJa2vkBNIAdZOGIvNuS9CHK JjGO.pdf.

30. Raosoft. Sample Size Calculator. [cited 2014 April 20]; Available from: http:// www.raosoft.com/samplesize.html

31. Quandt SA, Chen H, Grzywacz JG, Bell RA, Lang W, Arcury TA. Use of complementary and alternative medicine by persons with arthritis: results of the National Health Interview Survey. Arthritis Rheum. 2005; 53(5):748-55.

32. Grzywacz JG, Suerken CK, Quandt SA, Bell RA, Lang W, Arcury TA. Older adults' use of complementary and alternative medicine for mental health: findings from the 2002 National Health Interview Survey. J Altern Complement Med. 2006;12(5):467-73.

33. Edirne T, Arica SG, Gucuk S, Yildizhan R, Kolusari A, Adali E, Can M. Use of complementary and alternative medicines by a sample of Turkish women for infertility enhancement: a descriptive study. BMC Complement Altern Med. 2010;10:11

34. Bardaweel SK, Shehadeh M, Suaifan GA, Kilani MV. Complementary and alternative medicine utilization by a sample of infertile couples in Jordan for infertility treatment: clinics-based survey. BMC Complement Altern Med. 2013;13:35.

35. Al Asmi A, Al Maniri A, Al-Farsi YM, Burke DT, Al Asfoor FM, Al Busaidi I, A Breiki MH, Lahiri S, Braidy N, Essa MM, et al. Types and sociodemographic correlates of complementary and alternative medicine (CAM) use among people with epilepsy in Oman. Epilepsy Behav. 2013;29(2):361-6.

36. Yeh GY, Davis RB, Phillips RS. Use of complementary therapies in patients with cardiovascular disease. Am J Cardiol. 2006;98(5):673-80.

37. Elkins G, Fisher W, Johnson A. Mind-body therapies in integrative oncology. Curr Treat Options Oncol. 2010;11(3-4):128-40.

38. Oppenheim WL. Complementary and alternative methods in cerebral palsy. Dev Med Child Neurol. 2009;51 Suppl 4:122-9.

39. Montazeri A, Sajadian A, Ebrahimi M, Akbari ME. Depression and the use of complementary medicine among breast cancer patients. Support Care Cancer. 2005;13(5):339-42.

40. Merriam S, Muhamad M. Roles traditional healers play in cancer treatment in Malaysia: implications for health promotion and education. Asian Pac J Cancer Prev. 2013;14(6):3593-601.

41. Saydah SH, Eberhardt MS. Use of complementary and alternative medicine among adults with chronic diseases: United States 2002. J Altern Complement Med. 2006;12(8):805-12

42. Team V, Canaway R, Manderson L. Integration of complementary and alternative medicine information and advice in chronic disease management guidelines. Aust J Prim Health. 2011;17(2):142-9.

43. Hashempur MH, Heydari M, Mosavat SH, Heydari ST, Shams M. Complementary and alternative medicine use in Iranian patients with diabetes mellitus. J Integr Med. 2015;13(5):319-25. 
44. Zyoud SH, Al-Jabi SW, Sweileh WM. Scientific publications from Arab world in leading journals of Integrative and Complementary Medicine: a bibliometric analysis. BMC Complement Altern Med. 2015;15:308.

45. Younis MZ, Hamidi S, Forgione DA, Hartmann M. Rational use effects of implementing an essential medicines list in West Bank, Palestinian Territories. Expert Rev Pharmacoecon Outcomes Res. 2009;9(3):243-50.

46. Palestinian Ministry of Health. Palestinian Essential Drug List 2013. 2013 [cited 2016 January 22]; Available from: http://pharmacy.moh.ps/Content/ PDF/GXa4LIB4fU1MVPavE6Ceq6Ai_wijxbhTA93rak5SU4fpzuEjp.pdf

47. Osman NA, Hassanein SM, Leil MM, NasrAllah MM. Complementary and Alternative Medicine Use Among Patients With Chronic Kidney Disease and Kidney Transplant Recipients. J Ren Nutr. 2015;25(6):466-71.

48. Tangkiatkumjai M, Boardman H, Praditpornsilpa K, Walker DM. Reasons why Thai patients with chronic kidney disease use or do not use herbal and dietary supplements. BMC Complement Altern Med. 2014;14:473

49. Zhang H, Ho YF, Che CT, Lin ZX, Leung C, Chan LS. Topical herbal application as an adjuvant treatment for chronic kidney disease-a systematic review of randomized controlled clinical trials. J Adv Nurs. 2012;68(8):1679-91.

50. Saleem U, Ahmad B, Rehman K, Mahmood S, Alam M, Erum A. Nephroprotective effect of vitamin $\mathrm{C}$ and Nigella sativa oil on gentamicin associated nephrotoxicity in rabbits. Pak J Pharm Sci. 2012;25(4):727-30.

51. Yildiz F, Coban S, Terzi A, Savas M, Bitiren M, Celik H, Aksoy N. Protective effects of Nigella sativa against ischemia-reperfusion injury of kidneys. Ren Fail. 2010;32(1):126-31.

52. Ashtiani SC, Jafari M, Najafi H, Ahmadi M. Protective effects of Salvia Officinalis extract against gentamicin-induced nephrotoxicity in rat. J Kermanshah Univ Med Sci. 2013;17(4):212-20.

53. Nowack R, Nowak B. Herbal teas interfere with cyclosporin levels in renal transplant patients. Nephrol Dial Transplant. 2005;20(11):2554-6.

54. Nowack R. Herb-drug interactions in nephrology: documented and theoretical. Clin Nephrol. 2008;69(5):319-25.

55. Nowack R. Review article: cytochrome P450 enzyme, and transport protein mediated herb-drug interactions in renal transplant patients: grapefruit juice, St John's Wort - and beyond! Nephrology (Carlton). 2008;13(4):337-47.

56. Nowack R, Balle C, Birnkammer F, Koch W, Sessler R, Birck R. Impact of food and herbal medication on calcineurin inhibitor dose in renal transplant patients: a cross-sectional study. J Med Food. 2011;14(7-8):756-60.

57. Burrowes JD, Van Houten G. Use of alternative medicine by patients with stage 5 chronic kidney disease. Adv Chronic Kidney Dis. 2005;12(3):312-25.

58. Saad B, Azaizeh H, Abu-Hijleh G, Said O. Safety of traditional arab herbal medicine. Evid Based Complement Alternat Med. 2006;3(4):433-9.

59. Lin MY, Chiu YW, Chang JS, Lin HL, Lee CT, Chiu GF, Kuo MC, Wu MT, Chen HC, Hwang SJ. Association of prescribed Chinese herbal medicine use with risk of end-stage renal disease in patients with chronic kidney disease. Kidney Int. 2015;88(6):1365-73.

60. Akpan EE, Ekrikpo UE. Acute renal failure induced by Chinese herbal medication in Nigeria. Case Rep Med. 2015;2015:150204.

61. Combest W, Newton M, Combest A, Kosier JH. Effects of herbal supplements on the kidney. Urol Nurs. 2005;25(5):381-6. 403.

62. Asif M. A brief study of toxic effects of some medicinal herbs on kidney. Adv Biomed Res. 2012;1:44.

63. Wojcikowski K, Johnson DW, Gobe G. Medicinal herbal extracts - renal friend or foe? part one: the toxicities of medicinal herbs. Nephrology (Carlton). 2004;9(5):313-8.

64. Nowack R, Birck R. Complementary and alternative medicine is popular among chronic renal failure patients-renal teams must increase their competence to advise patients with respect to efficacy and safety. Evid Based Nurs. 2012;15(1):29-30.

65. Dahl NV. Herbs and supplements in dialysis patients: panacea or poison? Semin Dial. 2001;14(3):186-92.

66. Welder GJ, Wessel TR, Arant CB, Schofield RS, Zineh I. Complementary and alternative medicine use among individuals participating in research: implications for research and practice. Pharmacotherapy. 2006; 26(12):1794-801.

67. Huang JC, Li JH, Liu TX. [Effect of combined therapy with hypha Cordyceps and ginkgo leaf tablet on micro-inflammation in patients undergoing maintenance hemodialysis]. Zhongguo Zhong Xi Yi Jie He Za Zhi. 2008;28(6):502-4.
68. Guo D, Yu J. [Clinical study on the effect of TCM treatment in decreasing frequency of peritoneal dialysis]. Zhongguo Zhong Xi Yi Jie He Za Zhi. 1996;16(2):67-9.

69. Zhang HW, Lin ZX, Xu C, Leung C, Chan LS. Astragalus (a traditional Chinese medicine) for treating chronic kidney disease. Cochrane Database Syst Rev. 2014;10:Cd008369.

70. Yurtkuran M, Alp A, Yurtkuran M, Dilek K. A modified yoga-based exercise program in hemodialysis patients: a randomized controlled study. Complement Ther Med. 2007;15(3):164-71.

71. Tsai TJ, Lai JS, Lee SH, Chen YM, Lan C, Yang BJ, Chiang HS. Breathingcoordinated exercise improves the quality of life in hemodialysis patients. J Am Soc Nephrol. 1995;6(5):1392-400.

\section{Submit your next manuscript to BioMed Central and we will help you at every step:}

- We accept pre-submission inquiries

- Our selector tool helps you to find the most relevant journal

- We provide round the clock customer support

- Convenient online submission

- Thorough peer review

- Inclusion in PubMed and all major indexing services

- Maximum visibility for your research

Submit your manuscript at www.biomedcentral.com/submit 